
\title{
BReserch S Suare \\ Quality of Work Life and Associated Factors among Nurses Working in Wollega Zones Governmental Hospitals, West Ethiopia, 2018
}

Getu Mosisa ( $\sim$ getumosisa344@gmail.com )

Wollega University

Muktar Abadiga

Wollega University

Adugna Oluma

Wollega University

Bizuneh Wakuma

Wollega University

Research article

Keywords: Quality of work life, Nurses, Wollega Zones

Posted Date: May 1st, 2020

DOI: https://doi.org/10.21203/rs.3.rs-25726/v1

License: (c) (i) This work is licensed under a Creative Commons Attribution 4.0 International License.

Read Full License 


\section{Abstract}

\section{Background}

Quality of work-life refers to the extent to which members of a work organization can satisfy their personal needs through their work experience in the organization. High quality of working life is critical for healthcare organizations to attract and retain qualified, committed and motivated employees and also lead to high task performance. However, there are few studies regarding quality of work life among nurses in Ethiopia. The objective of this study was to assess quality of work life and associated factors among nurses working in Wollega Zones governmental hospitals, 2018.

Methods

Institutional based cross - sectional study design was conducted on 212 nurses working in wollega zones governmental hospitals from November to December, 2018. The study participants were selected by using simple random sampling techniques. The data was entered into Epi data version 3.1 and then exported into Statistical Package for the Social Sciences window version 20.0 for analysis. Multiple regression analysis was conducted to identify factors associated with quality of working life of nurses. Statistical significance was declared at $p<0.05$.

Result

A total of 212 nurses were involved in the study. The study revealed that about 108(50.5\% of nurses have good quality of work life. Income and dependent family were significantly associated with quality of work life. In this study, Nurses who have no dependent family were 2.72 (AOR $2.72,95 \%$ Cl: 1.38, 5.38) times more likely to have good quality of work life compared to those who have dependent family. Nurses whose monthly income 446-5294 were 2.39(AOR 2.39 95\% Cl: 1.08, 5.37) times more likely to have good quality of work life compared to those who got less than 3653 .

\section{Conclusion}

Nearly half of nurses were dissatisfied with the quality of their work life. The study revealed that monthly income and presence of dependent family showed significant association with quality of work life. Bringing up and maintaining a higher level of quality of work life among nurses is a key to promote job satisfaction and enhance quality of patient care.

\section{Background}

Quality of work-life refers to the degree to which members of a work organization can satisfy their personal needs through their work experience in the organization. It covers the person's feelings about every aspect of work including economic rewards, benefits, security, internal \& external equity, working conditions, career opportunity, decision authority, organizational \& interpersonal relationships, which are very meaningful in a person's life [1]. According to Brooks, quality of nursing work life is the degree to 
which registered nurses are able to satisfy important personal needs through their experiences in their work organization while achieving the organization's goals [2].

Quality of working life is normally considered as the real work situations including employee salary, facilities, health and safety issues, participating in decision making, management approach and job diversity and flexibility [3].Quality of work life contains 4 dimensions: Work Life/Home Life, Work Design Dimension, Work Context Dimension and Work World Dimension. Work Life/Home Life is defined as the interface between the life experiences of nurses in their place of work and in the home. Work Design is defined as the composition of nursing work and describes the actual work nurses do. Work Context is defined as the practice settings in which nurses' work and explores the impact of the work environment on both nurse and patient systems and Work World is defined as the effects of broad societal influences and changes on the practice of nursing [4].

Nursing is a very demanding profession and they have a vital role in delivering health care. Nurses are the most diverse and most abundant workforces in the health care system, they are responsible for and to make a quick decision about patient care and well-being. Improving the quality of working life of staff nurses is important to improve quality of care of the patients. The rapidly changing health care environment has had a consequence on the nursing work environment, workload, and quality of nursing work life $[5,6]$.

As indicated by studies conducted worldwide, more than one -third of respondents have a low level of quality of work life. About $45.7 \%$ of nurses in Iran have a low level of quality of work-life, in India, about $29.3 \%$ reported low level of quality of work-life $[6,7]$.

High quality of working life (QWL) is significant for healthcare organizations to attract and retain qualified, committed and motivated employees and also lead to high task performance $[8,9]$. Designing jobs exclusively for the needs of technology without recognizing the needs of workers is a challenge. The intervention which considers Quality of Work-Life helps the organization to use their worker's full potential, ensures comprehensive participation and engagement of workers, makes work easier, improves quality and increases efficiency $[10,11]$.. Improvement of quality of work-life among health care providers specifically nurses positively affecting patient outcomes [12]. Satisfied employees are working with more interest and they have more faithful to their organization. The dissatisfaction of nurses with their quality of work-life is the factors to leave their organization and may lead them to find another career opportunity [13].

Few studies were conducted previously on job satisfaction but it focuses mainly on likes and dislikes of the employee, the nursing work environment is not addressed in job satisfaction, today the quality of work-life gained much acceptance in the nursing profession [14]. However; little is known about the quality of work-life of nurses in Ethiopia. This cross - sectional study was conducted to assess the quality of work life and associated factors among nurses working in governmental hospitals of wollega zones. 


\section{Methods And Materials}

\section{Study setting and population}

The study was conducted in governmental Hospitals of Wollega Zones at Nekemte referral Hospital, Wollega University referral hospital, Ghimbi hospital, Nedjo Hospital, Shambu hospital, Dembi Dollo hospital and Arjo hospital from November to December 2018. Institution based cross - sectional study design was used. All nurses working in Wollega Zones governmental hospitals was source population and all sampled nurses from the total of nurses working in Wollega Zones governmental hospitals was the study population. Nurses who have been working for more than 6 months in the hospital were included in the study.

\section{Sample Size Determination and Sampling Techniques}

\section{Sample Size Determination}

The sample size of the study was calculated using formula for estimation of single population proportion. Since the source population was 458 nurses which were less than 10,000, finite population correction was needed and adding $10 \%$ non-response rate, the final

sample becomes 230 . The study participants were selected by simple random sampling methods.

\section{Data Collection Tool And Procedures}

A self-administered questionnaire that has two parts was applied for data collection. The first part contains socio-demographic characteristics such as sex, age, marital status, educational status, the experience of work, monthly income, dependent family (child/adult), and work unit. Part two contains questions related to the quality of work life. It was adapted from Brook's quality of work life questionnaire scale to measure the quality of working life [4]. It contains 42 items divided into four subscales: (a) work life/home life, (b) work design, (c) work context and (d) work world. The instrument asks respondent nurses how much they agree or disagree with each item on a 6-point scale, with 1 indicating 'strongly disagree', 2 'moderately disagree', 3 'disagree', 4 'agree', 5 'moderately agree', and 6 'strongly agree'. The 6point scale was merged to two categories as agree and disagree. Agree category contains positive responses (agree, moderately agree and strongly agree), and disagree category contains negative responses (strongly disagree, moderately disagree and disagree) $[4,15]$. In this study, cronbach's alpha for quality of work life items was checked and found to be 0.928 , which was in the acceptable level.

\section{Data processing and analysis}

After data collection, each questionnaire was checked visually for completeness and then entered into Epi Data Version 3.1 and was analyzed using SPSS version 20.0. Univariate descriptive analyses like 
percentages and frequency distributions were used in the form of tables and graphs to summarize the variables mean and the standard deviation was computed as well. A bivariate logistic regression analysis was carried out to assess association between the dependent and all the independent variables to identify candidate for multivariable analysis. Variables significant at $p<0.25$ were considered as candidate for the multivariable logistic regression analysis and then independent variables, which had a statistically significant association with the dependent variable at $P<0.05$, were entered to the final regression model. Results were reported as the odds ratios (OR) with respective $95 \% \mathrm{Cl}$.

\section{Data Quality Control}

The training was given for the supervisors to control the quality of the data to be collected. Pre-test was done on nurses working in Nekemte health center by taking $5 \%$ of sample size prior to the actual data collection and some modification were made.

\section{Result}

\section{Socio-demographic characteristics of the respondents}

A total of 212 nurses were involved in the study and provide a response rate of $92.17 \%$. From a total of 212 nurses majority of them $130(61.3 \%)$ were male. The mean age of the respondent was $(28.36+4.1)$. More than half, $57.5 \%$ of the study participants were between ages of 25-29 categories. Majority of the study participants $149(70.3 \%)$ were got married, about $140(66 \%)$ of them have Bachelor degree. Majority of the study participants $87(41 \%)$ had 6-10 years of work experience. Majority of them, $59(27.8 \%)$ nurses answered as they earned between 3653 to 4446 Ethiopian Birr. Majority of the study participants $163(76.9 \%)$ have dependent family. More than half of the study participants were working in inpatient (Table 1). 
Table 1

Socio-demographic characteristics of nurses working at Wollega Zone public hospitals, 2018

\begin{tabular}{|c|c|c|}
\hline Character & Frequency (n) & Percent (\%) \\
\hline \multicolumn{3}{|l|}{ Sex } \\
\hline Male & 130 & 61.3 \\
\hline Female & 82 & 38.7 \\
\hline \multicolumn{3}{|l|}{ Age } \\
\hline $20-24$ & 20 & 9.4 \\
\hline $25-29$ & 122 & 57.5 \\
\hline $30-34$ & 50 & 23.6 \\
\hline > 35 & 20 & 9.4 \\
\hline \multicolumn{3}{|l|}{ Marital status } \\
\hline Married & 149 & 70.3 \\
\hline Single & 63 & 29.7 \\
\hline \multicolumn{3}{|c|}{ Educational status } \\
\hline Diploma & 71 & 33.5 \\
\hline Bachelor degree & 141 & 66.5 \\
\hline \multicolumn{3}{|l|}{ Work experience } \\
\hline$<2$ years & 25 & 11.8 \\
\hline $2-5$ years & 71 & 33.5 \\
\hline $6-10$ years & 87 & 41 \\
\hline$>11$ years & 29 & 13.7 \\
\hline \multicolumn{3}{|l|}{ Monthly income } \\
\hline > 3653 & 56 & 26.4 \\
\hline $3653-4446$ & 59 & 27.8 \\
\hline $4446-5294$ & 52 & 24.5 \\
\hline > 5294 & 45 & 21.2 \\
\hline \multicolumn{3}{|l|}{ Work unit } \\
\hline OPD & 56 & 26.4 \\
\hline
\end{tabular}




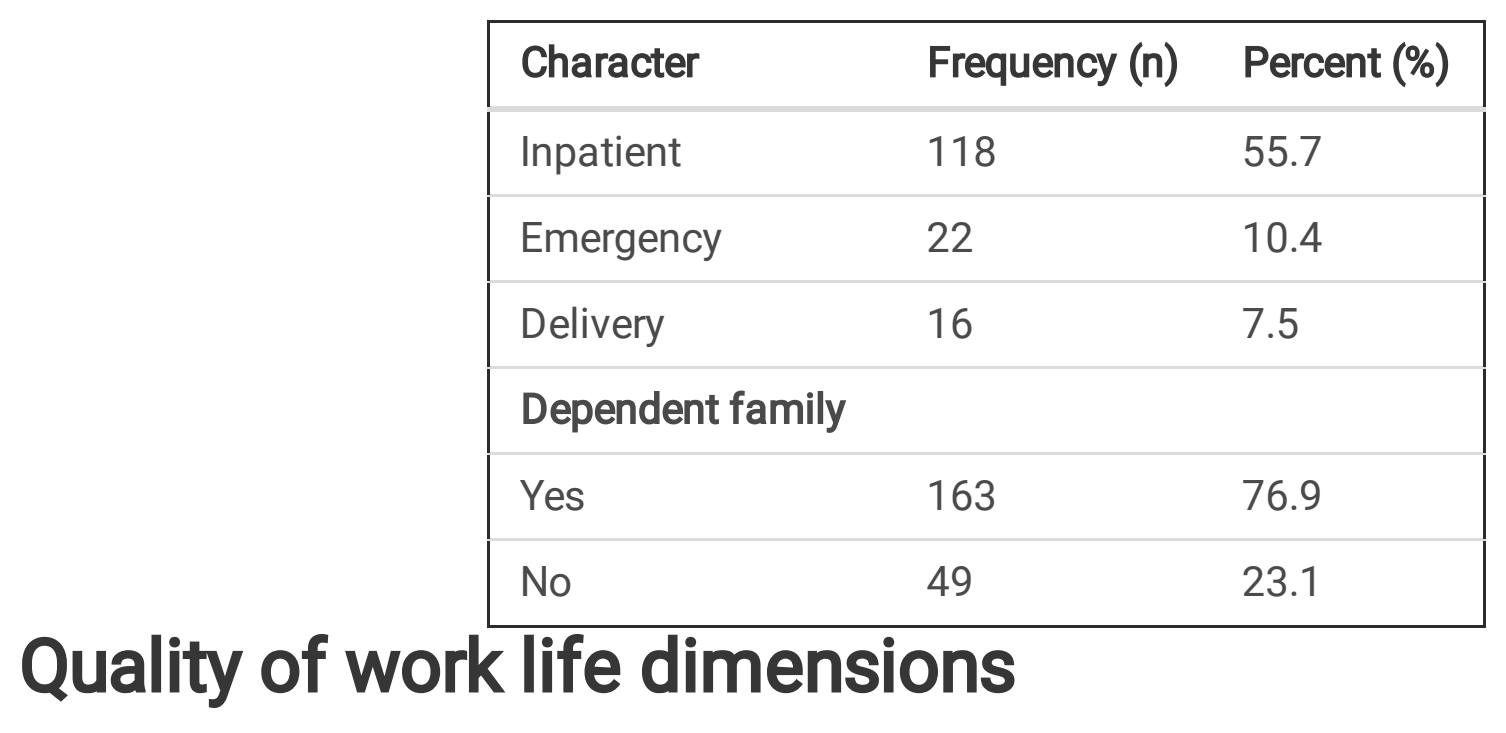

The four items Brook quality of work life score can range from 42-252. A low total scale score indicates a low quality of work life and a high total score indicates a high quality of work life. In this study the overall item score of quality of work life was range from 48-227 with a mean of $154.5+28.19$. The actual range of work life was from 8-40 with a mean of $24.53+6.01$, for work design the actual range was from $10-57$, mean $37.45+7.52$, work context range form $20-117$, mean $76.01+16.36$ and the actual range for work world range was from 5-28 with a mean of $16.5+3.85$ (Table 2).

Table 2

Over all scores and sub scores for quality of work life items among nurses working in Wollega zone public hospitals, 2018.

\begin{tabular}{|lllll|}
\hline Scale & Possible range & Actual range & Mean & SD \\
\hline Work life & $7-42$ & $8-40$ & 24.53 & 6.01 \\
\hline Work design & $10-60$ & $10-57$ & 37.45 & 7.52 \\
\hline Work context & $20-120$ & $20-117$ & 76.01 & 16.36 \\
\hline Work world & $5-30$ & $5-28$ & 16.5 & 3.85 \\
\hline Over all (42 item scale ) & $\mathbf{4 2 - 2 5 2}$ & $\mathbf{4 8 - 2 2 7}$ & $\mathbf{1 5 4 . 5}$ & $\mathbf{2 8 . 1 9}$ \\
\hline
\end{tabular}

\section{Description of quality of work life dimensions}

The 6-point scale was merged to two categories as agree and disagree. Agree category contains positive responses (agree, moderately agree and strongly agree), and disagree category contains negative responses (strongly disagree, moderately disagree and disagree).

\section{Work Life Dimension}

In this study about $111(52.4 \%)$ of nurses were responded as they are able to balance their work with family needs. However, more than half of nurses $125(59 \%)$ were not satisfied with their organizational 
policy for family leave.

\section{Work Design Dimension}

More than half of nurses 125(59\%) were not received adequate assistance from unlicensed support personnel. About 107(50.5\%) were not satisfied with their job. Majority, $159(75 \%)$ of nurses responded as their work is too heavy. About $168(79.2 \%)$ responded as they have autonomy in patient care decision and more than half $120(56.6 \%)$ responded as they perform many non-nursing tasks.

\section{Work Context Dimension}

In these contexts almost in all items nurses was responded as they are satisfied except in some items. About 118(55.7\%) nurses were not satisfied with lounge/break-area/locker room in their setting. About more than half $50.5 \%$ nurses responded as upper level management has respect for nurses.

\section{Work world dimension}

About $112(52.8 \%)$ of nurses responded as society has good image for their profession. However; majority of the nurses, $142(67 \%)$ were dissatisfied with their salary. More than half of them $123(58 \%)$ feel as their job is secure (Table 3$)$. 
Table 3

Description of the quality of work life scale items among nurses working in Wollega zone public hospitals, 2018

\section{QWL dimension}

Agree $n$

(\%)

Disagree

n (\%)

\section{Work life dimension}

I am able to balance work with my family needs.

111(52.4) 101(47.6)

I am able to arrange for child-care when I am at work.

121(57.1) 91(42.9)

I have energy left after work.

107(50.5) 105(49.5)

I feel that rotating schedules negatively affect my life.

101(47.6) 111(52.4)

My organization's policy for family-leave time is adequate.

$87(41)$

125(59)

I am able to arrange for day care for my elderly parents.

109(51.4) 103(48.6)

I am able to arrange for day care when my child is ill

120(56.6) 92(43.4)

Work design dimension

I receive a sufficient amount of assistance from unlicensed support personnel.

I am satisfied with my job.

$87(41)$

125(59)

My workload is too heavy.

105(49.5) 107(50.5)

I have autonomy to make patient care decisions.

159(75) 53(25)

I perform many non-nursing tasks.

168(79.2) 44(20.8)

I experience many interruptions in my daily work routine.

120(56.6) 92(43.4)

I have enough time to do my job well.

140(66) 72(34)

There are enough RNs in my work setting.

116(54.7) 96(45.3)

126(59.4) 86(40.6)

I am able to provide good quality patient care.

181(85.4) 31(14.6)

I receive quality assistance from unlicensed support personnel

96(45.3)

116(54.7)

\section{Work context dimension}

I am able to communicate well with my nurse manager/supervisor.

171(80.7)

$41(19.3)$

I have adequate patient care supplies and equipment.

112(52.8) 100(47.2)

My nurse manager/supervisor provides adequate supervision.

143(67.5) 69(32.5)

Friendships with my co-workers are important to me.

172(81.1) 40(18.9)

My work setting provides career advancement opportunities

125(59)

$87(41)$ 


\section{QWL dimension}

Agree $n$

(\%)

I feel like there is teamwork in my work setting.

I feel like I belong to the "work family."

I am able to communicate with other therapists

I receive feedback on my performance from my nurse manager/supervisor.

I am able to participate in decisions made by my nurse manager/supervisor.

I feel respected by physicians in my work setting.

The nurses' lounge/break-area/locker room in my setting is comfortable.

I have access to degree completion programs through my work setting.

I receive support to attend in-services and continuing education programs.

I communicate well with the physicians in my work setting.

I am recognized for my accomplishments by my nurse manager/supervisor.

Nursing policies and procedures facilitate my work.

I feel the security department provides a secure environment.

I feel safe from personal harm (physical, emotional, or verbal) at work.

I feel that upper-level management has respect for nursing.

Work world dimension

I believe that, in general, society has the correct image of nurses

My salary is adequate for my job given the current job market conditions

I would be able to find the same job in another organization with about the same salary and benefits

I feel my job is secure

I believe my work impacts the lives of patients

\begin{tabular}{ll}
$157(74.1)$ & $55(25.9)$ \\
\hline $149(70.3)$ & $63(29.7)$ \\
\hline $166(78.3)$ & $46(21.7)$ \\
\hline $162(76.4)$ & $50(23.6)$ \\
\hline $160(75.5)$ & $52(24.5)$
\end{tabular}

163(76.9) 49(23.1)

94(44.3) 118(55.7)

114(53.8) 98(46.2)

112(52.8) 100(47.2)

160(75.5) 52(24.5)

145(68.4) 67(31.6)

138(65.1) 74(34.9)

115(54.2) 97(45.8)

121(57.1) 91(42.9)

105(49.5) 107(50.5)

112(52.8) 100(47.2)

70(33) 142(67)

99(46.7) 113(53.3)

123(58)

89(42)

132(62.3) $\quad 80(37.7)$

\section{Level of quality of work life}

In this study, about $108(50.9 \%)$ nurses have good level of quality of work life while the rest $104(49.1 \%)$ have low level of QWL (Fig. 1).

Factors associated with Quality of work life 
In bivariate analysis, marital status, work experience, income and dependent family showed significant association at $p$-value of 0.25 .Finally; in multivariable analysis only income and presence of dependent family were significantly associated with quality of work life at p-value less than 0.05 . In this study, Nurses those who have no dependent family were 2.72 (AOR $2.72,95 \% \mathrm{Cl}: 1.38,5.38$ ) times more likely to have good quality of work life compared to those who have dependent family. Nurses who have monthly income 446-5294 were 2.39(AOR $2.3995 \% \mathrm{Cl}$ : 1.08, 5.37) times more likely to have good quality of work life compared to those who have less than 3653 (Table 4). 
Table 4

Bivariate and multivariable analysis of factors associated with quality of work life among nurses working in Wollega Zones Public Hospital, 2018.

\begin{tabular}{|c|c|c|c|c|c|}
\hline \multirow[t]{2}{*}{ Characteristics } & \multicolumn{2}{|c|}{ Quality of work life } & \multirow[t]{2}{*}{ COR $(95 \% \mathrm{Cl})$} & \multirow[t]{2}{*}{ AOR (95\% Cl) } & \multirow[t]{2}{*}{ P-Value } \\
\hline & Good n (\%) & Poor n (\%) & & & \\
\hline \multicolumn{6}{|l|}{ Sex } \\
\hline Male & $67(51.5)$ & $63(48.5)$ & $1.06(0.6,1.85)$ & & 0.82 \\
\hline Female & $41(50)$ & $41(50)$ & 1 & 1 & \\
\hline \multicolumn{6}{|l|}{ Age } \\
\hline $20-24$ & $13(65)$ & $7(35)$ & $1.24(0.34,4.46)$ & & 0.74 \\
\hline $25-29$ & $64(52.5)$ & $58(47.5)$ & $0.74(0.28,1.93)$ & & 0.53 \\
\hline $30-34$ & 19(38) & $31(62)$ & $0.41(0.14,1.18)$ & & 0.09 \\
\hline$>35$ & $12(60)$ & $8(40)$ & 1 & 1 & \\
\hline \multicolumn{6}{|l|}{ Marital status } \\
\hline Married & $70(47)$ & 79(53) & 1 & 1 & \\
\hline Single & $38((60.3)$ & 25(39.7) & $1.7(0.94,3.12)$ & $1.55(0.76,3.13)$ & 0.22 \\
\hline \multicolumn{6}{|c|}{ Educational status } \\
\hline Diploma & $39(54.9)$ & $32(45.1)$ & 1 & & \\
\hline Bachelor degree & $69(48.9)$ & $72(51.1)$ & $0.78(0.44,1.39$ & & 0.41 \\
\hline \multicolumn{6}{|l|}{ Work experience } \\
\hline$<2$ years & $15(60)$ & $10(40)$ & 1 & 1 & \\
\hline $2-5$ years & $40(56.3)$ & $31(43.7)$ & $0.86(0.34,2.17)$ & $0.58(0.2,1.58)$ & 0.29 \\
\hline $6-10$ years & $35(40.2)$ & $52(59.8)$ & $0.45(0.18,1.11)$ & $0.38(0.14,1.02)$ & 0.06 \\
\hline > 11 years & $18(62.1)$ & 11(37.9) & 1.09(0.36, & $0.92(0.27,3.03)$ & 0.8 \\
\hline \multicolumn{6}{|l|}{ Monthly income } \\
\hline$>3653$ & $23(41.1)$ & $33(58.9)$ & 1 & 1 & \\
\hline $3653-4446$ & $30(50.8)$ & $29(49.2)$ & $1.48(0.71,3.1)$ & $1.65(0.77,3.52)$ & 0.19 \\
\hline $4446-5294$ & $32(61.5)$ & $20(38.5)$ & $2.29(1.06,4.96)$ & $2.39(1.08,5.27)^{\star}$ & 0.03 \\
\hline > 5294 & $23(51.1)$ & $22(48.9)$ & $1.5(0.68,3.3)$ & $1.64(0.73,3.7)$ & 0.23 \\
\hline
\end{tabular}

*Shows statistically significant at p-value 0.05 . 


\begin{tabular}{|llllll|}
\hline Characteristics & \multicolumn{2}{l}{ Quality of work life } & COR (95\% Cl) & AOR (95\% Cl) & P-Value \\
\cline { 2 - 4 } & Good n (\%) & Poor $\mathbf{n}(\%)$ & & \\
\hline Work unit & & & 1 & \\
\hline OPD & $29(51.8)$ & $27(48.2)$ & 1 & 0.8 \\
\hline Inpatient & $59(50)$ & $59(50)$ & $0.93(0.49,1.76)$ & 0.88 \\
\hline Emergency & $11(50)$ & $11(50)$ & $0.93(0.35,2.49)$ & 0.75 \\
\hline Delivery & $9(56.2)$ & $7(43.8)$ & $1.19(0.39,3.66)$ & \\
\hline Dependent family & & & & 1 & \\
\hline Yes & $74(45.4)$ & $89(54.6)$ & 1 & $2.73(1.38,5.39)^{*}$ & 0.003 \\
\hline No & $34(69.4)$ & $15(30.6)$ & $2.72(1.38,5.38)$ & \\
\hline *Shows statistically significant at p-value 0.05. & & & \\
\hline
\end{tabular}

\section{Discussion}

This study was aimed to assess the quality of work-life and associated factors among nurses working at wollega zone governmental hospitals. In this study the overall item score of quality of work life ranges from 48-227 with a mean of $154.5 \pm 28.19$. About half of nurses $(50.1 \%)$ have good quality of work life. This is in line with study conducted in West Bengal, India which showed about $59.3 \%$ of nurses have higher level of quality of work life(16). Again study conducted in Hong Kong showed as respondents had a slightly higher than average score on the quality of work life (17). However; study conducted in Ethiopia, Hawassa town nurses showed about $67.2 \%$ of nurses were dissatisfied by their work life, and their level of quality life was lower than this study (18). The reason for the discrepancy between these studies might be the difference in institution facilities.

In this study monthly income and having dependent family showed significant association with good quality of work life. The current study showed a significant association between monthly income and quality of work life. Nurses with higher monthly payment were more satisfied with their work life. About $67 \%$ of nurses reported as their salary is not adequate for their job given the current job market conditions and majority of them $142(67 \%)$ dissatisfied with their salary. This is supported with the finding of Saudi Arabia (15), Ethiopia (18), Iran (7) and Thailand (19).

Nurses who have dependent family were not satisfied with their quality of work life. About 101(47.6\%) of nurses reported as they are not balance their work with their family needs and more than half $125(59 \%)$ of them were not satisfied with adequacy of their organization's policy for family-leave time. This is supported with the findings of Saudi Arabia (15) and Bangalore Hospital (20). This indicated that nurses need time to give care to their family; they should balance their work-life with their family needs. 
In this study age, educational level, work experience, work unit, sex and marital status didn't show statistical significance at $p$-value 0.05 . But in different studies these variables showed significant association with quality of work life. Educational level showed significant association with quality of work life. Study conducted in Saudi Arabia, Hawassa Town and Theni \& Dindigul district (15, 18 and 21) showed, nurses with higher educational level were reported a better quality of work life. In contrary to this, study conducted at west Bengal, India showed Nurses with lower education level experienced better QWL than nurses with higher education (16). Regarding work experience, more experienced nurses were more satisfied with their QWL $(15,22$, and 23). The difference between the current and above mentioned study might be due to the difference in health institution setup and policy of the countries.

\section{Limitation}

Due to the cross-sectional nature of the data, the study cannot show cause and effect relationship between quality of work-life and socio-demographic characteristics. Due to the lack of adequate similar studies in our country, the comparison was made with other countries findings.

\section{Conclusions}

Nearly, half of nurses were dissatisfied with the quality of their work life. The study revealed that monthly income and dependent family showed a significant association with the quality of work life. Bringing up and maintaining a higher level of quality of work-life among nurses is a key to promote job satisfaction and enhance the quality of patient care.

\section{Declarations}

\section{Acknowledgment}

We would like to acknowledge Wollega University for financial support. We are also grateful to the study participants who voluntarily agreed to be interviewed and participated in the study.

\section{Funding}

The research was funded by Wollega University.

\section{Availability of data and materials}

The data used during the current study are available from the corresponding author on request.

\section{Authors' Contributions}

GM was involved in conceptualization of the study, participated in its design, and performed result writing, analyzing the finding and writing the manuscript. MA participated in its design, performed result writing, analyzing the finding and writing the manuscript. BW participated in analyzing the finding, 
supervision of data collection and the review of the final manuscript. AO involved in supervision of data collection and the review of the final manuscript. All authors read and approved the final manuscript.

\section{Ethics approval and consent to participate}

The study was reviewed and approved by the Institutional Review Boards of Wollega University Ethical review board. Written informed consent was obtained from the study participants.

\section{Consent for publication}

Not applicable

\section{Competing Interests}

The authors declare that they have no competing interests.

\section{Abbreviations}

QNWL: Quality of nurse work life, QWL: Quality of work life, SPSS: Statistical Package for Social Science, WU: Wollega University, WURH: Wollega University Referral Hospital

\section{References}

1. P. GargNeetu Munjal, Preeti Bansal, Akshay Kirti Singhal. Quality of work life. International Journal of Physical and Social Sciences. Volume 2, Issue 3, March 2012, 231-42.

2. Brooks BA: Development of an instrument to measure quality of nurses' work life. University of Illinois at Chicago: Health Sciences Center; 2001.

3. Nagaraju Battu,G. Karthik Chakravarthy. Quality of work life of nurses and paramedical staff in hospitals. International Journal of Business and Administration Research Review, Vol.2, Issue.4, JanMarch, 2014, 200-207.

4. Brooks BA, Anderson MA: Defining quality of nursing work life. Nurs Econ 2005, 23(6):319-326.

5. Nizar B. Said, Filipe Nave, and Filomena Matos. The Quality of Working Life among Nurses in Pediatric Setting. The European Proceedings of Social \&Behavioral Sciences. January, 2015.

6. N.P. A study on quality of work life among private hospital nurses with special reference to mannarkkad municipality, palakkad district. International Journal of Research - Granthaalayah, 2017,5(4), 128-134.

7. Eslamian J, Akbarpoor AA, Hoseini SA. Quality of work life and its association with workplace violence of the nurses in emergency departments. Iranian Journal of Nursing and Midwifery Research 2015; 20:56-62.

8. Ali Mohammad Mosadeghrad, Ewan Ferlie and Duska Rosenberg.A study of relationship between job stress, quality of working life and turnover intention among hospital employees. Health Services 
Management Research 2011; 24: 170-181

9. Soliha Fathimath, Ratanawadee Chontawan,Bunpitcha Chitpakdee. Quality of Work Life and Job Performance among Nurses in the Tertiary Care Hospital, Maldives.106-118.

10. S. Nanjundes waraswamy, D. R. Swamy. Review of literature on quality of work life. International Journal for Quality Research 7(2) 201-214.

11. Molouk Jaafarpour, Ali Khani, Mohammad Reza Mahmodian. Evaluation of the quality of nursing work life and its association with job burnout in Isfahan University of Medical Sciences. International Journal of Epidemiologic Research, 2015; 2(1): 30-39.

12. Santhirani Nagammal, Abdulqadir . Nashwan, Sindhumole LK Nair, Anupama Susmitha. Quality of working life of nurses in a tertiary cancer center in Qatar. Global journal of medicine and governmental health. 6, No. 12017.

13. Ali Mohammad Mosadeghrad. Quality of working life and turnover intentions: implications for nursing management. International Journal of Research in Nursing 4 (2): 47-54, 2013.

14. Dinta Suresh. Quality of Nursing Work Life among nurses working in selected government and private hospitals in Thiruvananthapuram. October 2013.

15. Almalki et al.: Quality of work life among primary health care nurses in the Jazan region, Saudi Arabia: a cross-sectional study. Human Resources for Health 2012 10:30.

16. Miss Mamata Prasad. An evaluation of the quality of work life: A study of the governmental sector nurses in West Bengal. Volume No. 6 Issue No.2 Year:

17. M Chow. Assessing the quality of nursing work life in hongkong.HNE Handover for Nurses and Midwives Vol. 8, No. 2 (2015) Special Issue.

18. Lolemo Kelbiso, Admasu Belay and Mirkuzie Woldie. Determinants of Quality of Work Life among Nurses Working in Hawassa Town Governmental Health Facilities, South Ethiopia: A Cross-Sectional Study. Nursing Research and Practice Volume 2017, https://doi.org/10.1155/2017/5181676

19. Patcharee Komjakraphan, Kansunaphatr Balthip, Piyanuch Jittanoon. Quality of Work Life among Nurse Practitioners Working at Primary Care Setting in Thailand. Songklanagarind Journal of Nursing, 2017 Volume 37 Supplement: 98-105

20. Ramesh N, Nisha C, Josephine AM, Thomas S, Joseph B. A Study on Quality of Work Life among Nurses in a Medical College Hospital in Bangalore. Natl J Community Med 2013; 4(3): 471-474.

21. Saravana Priya. Quality of working life of female staff nurses in Theni \& Dindigul district.Vol. 2 No. 4 April 2015.

22. Tayebeh Moradi ;Farzaneh Maghaminejad; Ismail Azizi-Fini. Quality of Working Life of Nurses and its Related Factors. Nurs Midwifery Stud. June 2014; 3(2).

23. Thakre SB, Thakre SS, Thakre SN. Quality of work life of nurses working at tertiary health care institution: a cross sectional study. Int J Community Med Governmental Health 2017; 4:1627-36.

\section{Figures}




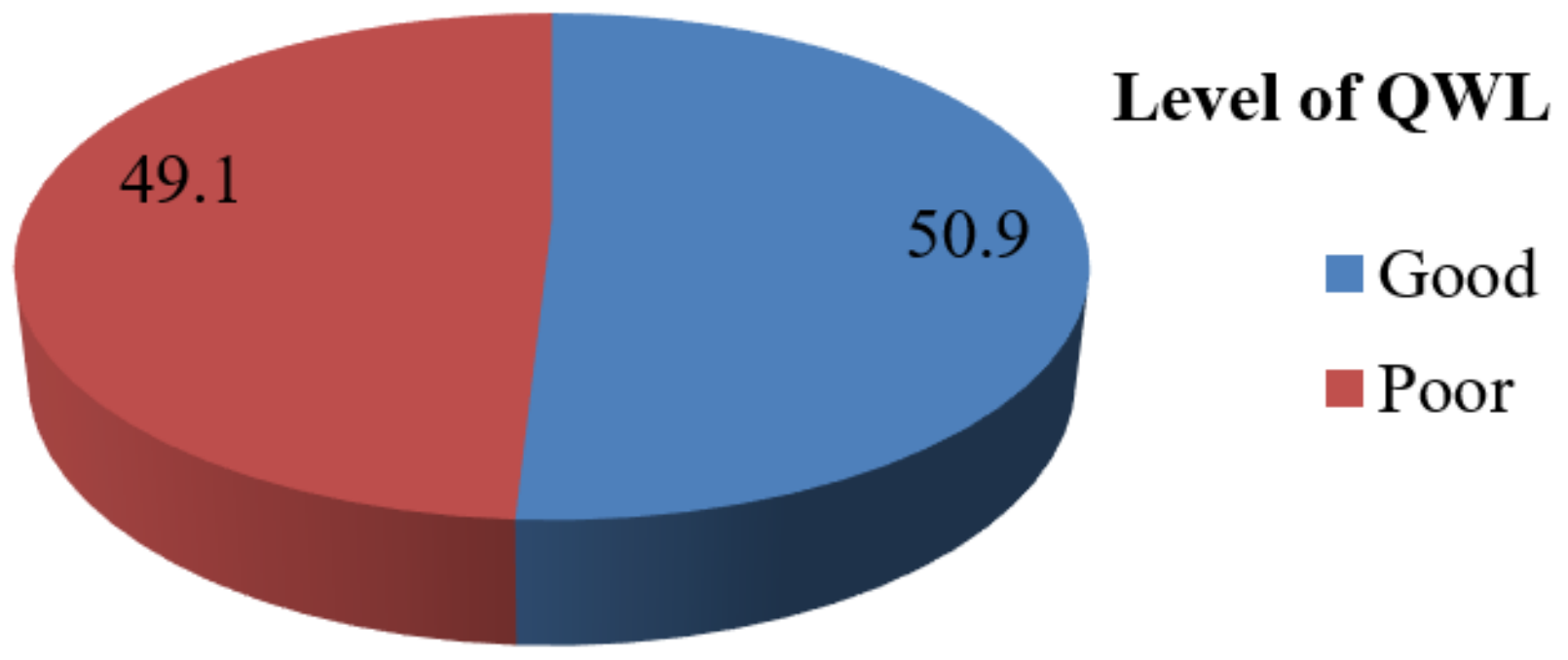

Figure 1

Quality of work life status of nurses working in Wollega Zones Public Hospital, 2018. 